\title{
Numerical modelling of residual stress redistribution induced by TIG-dressing
}

\author{
P. Ferro, F. Bonollo \\ University of Padova, Italy \\ paolo.ferro@unipd.it, bttps://orcid.org/0000-0001-8682-3486 \\ franco.bonollo@unipd.it, https://orcid.org/0000-0002-7196-2886
}

F. Berto

University of Trondheim (NTNU), Norway

filippo.berto@ntnu.no, https://orcid.org/0000-0002-4207-0109

\author{
A. Montanari \\ University of Rome, Italy \\ roberto.montanari@uniroma2.it,bttps://orcid.org/0000-0001-7791-4431
}

\begin{abstract}
TIG-dressing is a technique used to improve the fatigue strength of welded joints by a remelting of the weld toe region that promotes both a smoother transition between the plate and the weld crown and a residual stress redistribution. These effects are very hard to be quantified by numerical simulation since a highly coupled thermo-fluid-mechanical analysis is required. However, if the final weld toe geometry is supposed to be known or a-posteriori measured, a simplified numerical method can be used to simulate the residual stress redistribution that uses the activation-deactivation function of elements. This technique is applied to a real steel weldment and the results, in terms of phases proportions and residual stress redistribution, were found in good agreement both with data coming from metallurgical analysis and the improved fatigue strength observed on welded joints after the TIG-dressing operation.
\end{abstract}

KEYwORDS. Numerical modelling; Welding; TIG-dressing; Residual stress; Microstructure; Phase transformation

\section{open Access}

Citation: Ferro, P., Berto, F., Bonollo, F., Montanari, R., Numerical modelling of residual stress redistribution induced by TIGdressing, Frattura ed Integrità Strutturale, 47 (2019) 221-230.

Received: 17.08 .2018

Accepted: 21.09 .2018

Published: 01.01.2019

Copyright: (c) 2019 This is an open access article under the terms of the CC-BY 4.0 , which permits unrestricted use, distribution, and reproduction in any medium, provided the original author and source are credited.

\section{INTRODUCTION}

everal studies have demonstrated that unwelded plain material shows a linear relation between static strength and fatigue strength, but that the presence of notches results in a reduction of the fatigue strength. As a result, the fatigue strength of different steel grades is usually assumed to be equal in design codes. The low fatigue strength of 
welded joints compared to parent material, is due to different reasons, the most important of which is the stress concentration at the weld toe or weld root. For this reason, some techniques, aimed to improve the fatigue strength of welded joints, were developed [1]. They act mainly on two aspects: 1) the geometrical variation of the weld bead and 2) the reduction of the stress concentration factors. Among these techniques, the TIG-dressing is probably the most used and consists in the re-melting of the weld toe by means of the TIG heat source (without filler metal) [2-4]. Such operation promotes a smoother transition between the plate and the weld crown and thus a reduction of the stress concentration factor as well as a residual stress redistribution. Furthermore it doesn't affect significantly the angular distortion of the joint because of the reduced dimensions of the remelted zone. Especially the reduction of weld flaws and inclusions in combination with the increase in weld toe radius is assumed to create the beneficial behavior of TIG-dressed specimens when compared with as-welded specimens. Evidence of beneficial aspects of TIG-dressing against the fatigue strength of welded joints comes from literature. Dahle [5] found an increase in fatigue strength at two millions cycles ranging from $10 \%$ to $90 \%$ according to the steel grade and being the largest increment obtained with high strength steels. Similar results came from the work of Pedersen et al. who reported an increase in fatigue strength of $70 \%$ at two millions cycles [6]. Further evidences about the positive effect of TIG-dressing on fatigue strength of welded joints were published by Haagensen et al. [7] who observed an average increase of $44 \%$ in the fatigue strength of a fillet weld joint.

Despite the great number of fatigue tests performed in the past in order to assess the positive effects of TIG-dressing on welded joints, the residual stress assessment obtained either by means of experimental technique or numerical models is still lacking in literature. Compared to the numerical models of welding processes developed in the last years [8-14], the numerical simulation of TIG-dressing process is particularly complex because it requires a high coupling between thermometallurgical-fluid analysis and mechanical analysis. The weld bead geometrical variation induced by re-melting is influenced by the weldment distortions during TIG-dressing and vice-versa. For this reason, it was recently published in literature a numerical model of the TIG-dressing process that simplifies a lot the computation by using the activationdeactivation function of elements [15]. In this way, it is possible to avoid the fluid analysis, but the weld toe geometrical variation has to be 'a priori' known by means of welding and TIG-dressing trials. Such model is applied in this work to a real weldment and the results in terms of metallurgical and mechanical properties are compared and discussed.

\section{MATERIALS AND METHODS}

$\mathrm{F}$ ig. 1 shows a schematic of the welded joint cross section. Two $16 \mathrm{~mm}$ thick plates were fillet welded with a $12 \mathrm{~mm}$ thick plate by means arc welding. The chemical composition of plates and fusion zone (FZ) was measured by the quantometer Foundry-Master Pro and results are summarized in Tab. 1 where it is observed the greater amount of alloy elements in the 12 thick plate compared to that of the $6 \mathrm{~mm}$ thick one.

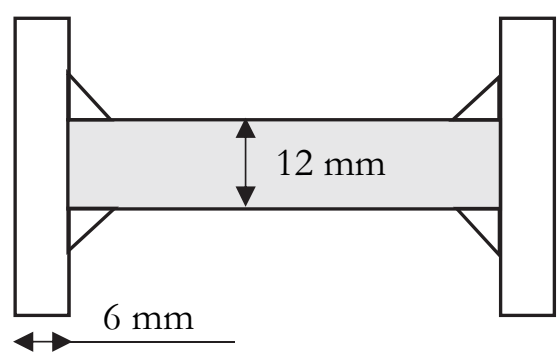

Figure 1: Schematic of the transversal section of the analyzed joints

\begin{tabular}{cccccccccc}
\hline & Fe & C & Si & Mn & P & S & Ni & Al & Cu \\
Parent Metal (plates 12 mm thick) & Bal. & 0.1223 & 0.0101 & 1.3467 & 0.0168 & 0.0161 & 0.0253 & 0.0378 & 0.0502 \\
Parent Metal (plates 6 mm thick) & Bal. & 0.0756 & 0.0128 & 1.1575 & 0.0143 & 0.0073 & 0.0056 & 0.0285 & 0.0087 \\
Fusion Zone & Bal. & 0.0892 & 0.4453 & 1.3800 & 0.0186 & 0.0142 & 0.0181 & 0.0083 & 0.0549 \\
\hline
\end{tabular}

Table 1: Chemical composition of the plates ( $\mathrm{wt} \%)$. 
Metallographic analysis was carried out by means of optical microscope (OM) and Environmental Scanning Electron Microscope (ESEM). Vickers microhardness profiles were performed across the FZ to support the microstructure interpretation.

\section{NUMERICAL MODEL}

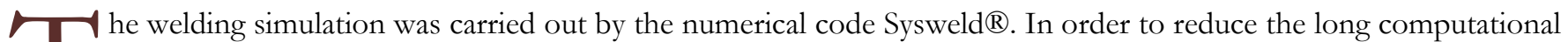
time required for a multi-pass welding thermo-mechanical transient analysis, a $2 \mathrm{D}$ model was adopted under generalized plane strain condition. A half cross-section was modeled according to the scheme shown in Fig. 1. The mesh, shown in Fig. 2 and obtained as a result of the sensitivity analysis, consists of 5436 four nodes elements. In order to take into account the effect of filler metal the geometrical variation of the weld toe induced by TIG-dressing, different element groups are created. By referring to Fig. 2, the black elements belong to the parent metal and are always active during simulation; the red ones define the filler metal and are activated during welding, while the blue elements groups are activated only during TIG-dressing and are used to simulate the smoothing effect induced by the remelting of the material.

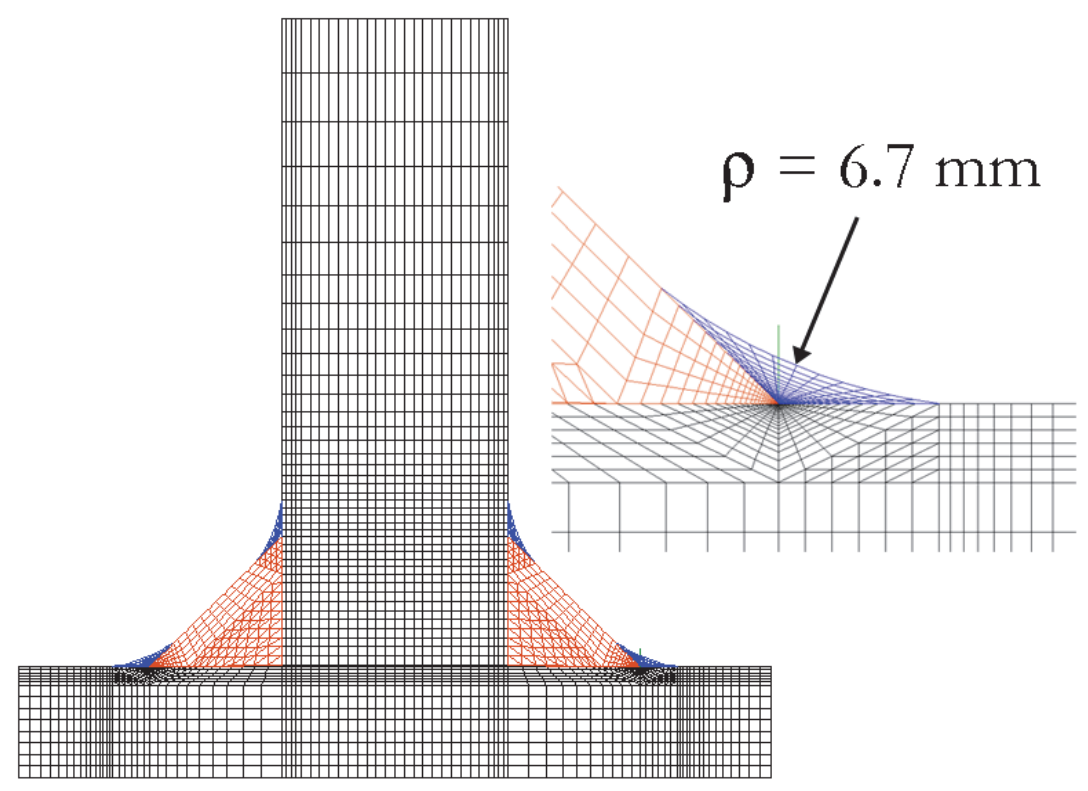

Figure 2: Mesh of the model with elements groups

The weld toe was modeled with a V-notch angle $(2 \alpha)$ equal to $135^{\circ}$ [16]. The toe-radius ( $\rho$ ) is equal to $0 \mathrm{~mm}$ in the aswelded condition and $6.7 \mathrm{~mm}$ after TIG-dressing treatments. This last value was obtained by averaging the measurements carried out on real samples. It is noted that a high-density mesh is used near the weld toe in order to capture the residual stress singularity induced by welding (the minimum element size was $5 \times 10^{-5} \mathrm{~mm}$ ). The different welding and TIG-dressing operations were sequentially performed according to Fig. 3. Thermo-metallurgical and mechanical properties of both filler and parent metals were taken from Sysweld data-base. Filler and parent metals alloys were chosen according to the chemical compositions reported in Tab. 1.

With the aim to include the metallurgical effects, in the present analysis the following microstructural constituents were considered: martensite, bainite, ferrite-pearlite, tempered martensite, tempered bainite and austenite. They were modelled by means of the Leblond-Devaux [17] and Koistinen-Marburger [18] equations according to their diffusional or nondiffusional feature. The simplifying assumptions were made that tempered bainite has the same properties as ferrite and that tempered martensite is similar in properties to bainite. The heat source was modelled using a double ellipsoid power density distribution function given by Goldak et al. [19] (Eqn. 1) that has been used previously in published literature for arc welding simulation [14]. 


$$
q_{g}(x, y, t)=\frac{6 \sqrt{3} f_{1,2} Q}{\pi \sqrt{\pi} a b c_{1,2}} e^{-\frac{3 x^{2}}{a^{2}}} e^{-\frac{3 y^{2}}{b^{2}}} e^{-\frac{3[v(\tau-t)]^{2}}{c_{1,2}^{2}}}
$$

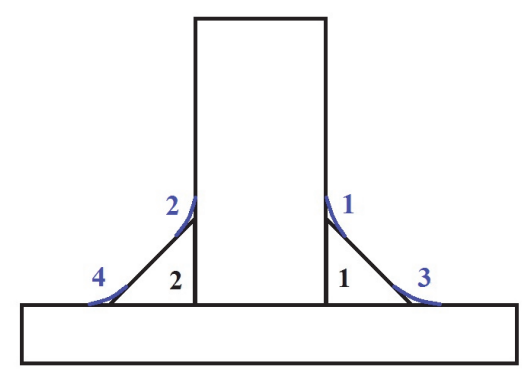

Figure 3: Welding and TIG-dressing operations sequence.

The meaning of the symbols in Eqn. (1) and their values are summarized in Tabs. 2 and 3.

\begin{tabular}{clc}
\hline $\mathrm{Q}^{*}$ & Power Input[W] & $*$ \\
$\eta$ & Efficiency & 0.64 \\
$\mathrm{Q}$ & Absorbed power [W], with $\mathrm{Q}=\eta^{*}$ & - \\
$\mathrm{a}$ & & $*$ \\
$\mathrm{~b}$ & Molten pool dimensions [mm] & $*$ \\
$\mathrm{c}_{1}$ & & 2.3 \\
$\mathrm{c}_{2}$ & & 7.9 \\
$\mathrm{f}_{1}$ & Constants for the energy distribution of the heat flux & 0.6 \\
$\mathrm{f}_{2}$ & & 1.4 \\
$\mathrm{v}$ & Welding speed [mms $\left.{ }^{-1}\right]$ & 2 \\
& TIG-dressing speed[mms $\left.{ }^{-1}\right]$ & 3 \\
& Total duration of time before the welding source has & $*$ \\
\hline & traversed the transverse cross section of the plate [s] & \\
\hline
\end{tabular}

Table 2: Goldak's source parameters. * indicates that the value used depends on the process (see Tab. 3 ). The high value of $\tau$ for TIG-dressing includes the time necessary for the weld to cool to room temperature after welding

\begin{tabular}{rcccc}
\hline & $\mathrm{Q}^{*}[\mathrm{~W}]$ & $\mathrm{a}[\mathrm{mm}]$ & $\mathrm{b}[\mathrm{mm}]$ & $\tau[\mathrm{s}]$ \\
TIG welding 1 & 4500 & 8 & 11 & 5 \\
TIG welding 2 & 4500 & 8 & 11 & 3005 \\
TIG-dressing 1 & 960 & 6 & 3 & 6005 \\
TIG-dressing 2 & 960 & 6 & 3 & 7065 \\
TIG-dressing 3 & 960 & 6 & 3 & 8125 \\
TIG-dressing 4 & 960 & 6 & 3 & 9185 \\
\hline
\end{tabular}

Table 3: Heat source parameters given as a function of the weld process.

The molten-remolten effect was simulated by incorporating a function that clears the history of an element once the temperature exceeds the melting temperature, which was taken as $1500^{\circ} \mathrm{C}$. Radiative heat loss (using the StephanBoltzmann law) and convective heat loss (using a convective heat transfer coefficient equal to $25 \mathrm{~W} / \mathrm{m}^{2} \mathrm{~K}$ ) have been applied at the boundary (external surfaces) of the plates to be joined. In the mechanical computation the weldment was considered isostatically clamped. Finally, a sequentially coupled thermo-metallurgical and mechanical analysis was

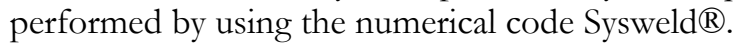




\section{RESULTS AND DISCUSSION}

$\mathrm{F}$ ig. 4 shows the weld toe geometry before and after TIG-dressing. As supposed, the V notch angle was $135^{\circ}$ while the weld toe radius was found to be close to zero after welding and about $6.7 \mathrm{~mm}$ after TIG-dressing. It shows the effectiveness of such post-welding operation in promoting a smoother transition between the plate and the weld crown.
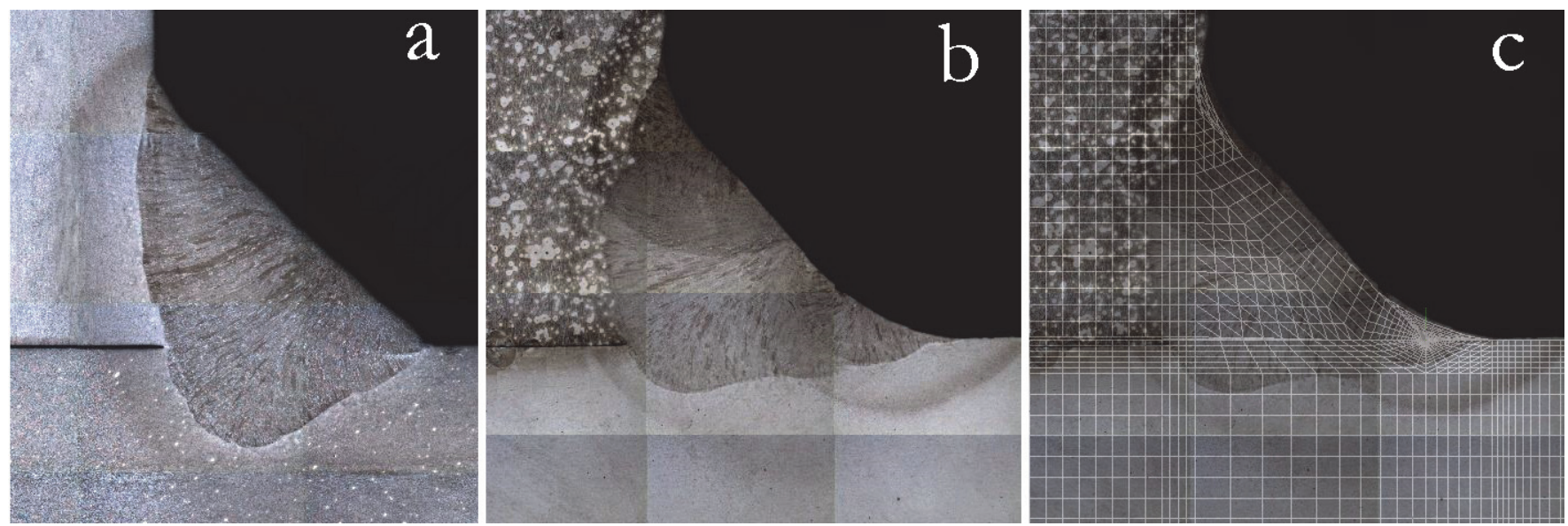

Figure 4: Macrograph of the fillet welding before (a) and after (b) TIG-dressing. Comparison between real and modeled geometry (c).

The FZ microstructure consists of acicular and Widmanstätten ferrite with islands of allotriomorphic ferrite both in the as-welded and post-welding treated joint (Fig. 5). It is in agreement with the microstructure observed in low carbon steels welded joints [20]. In the range between $800-300{ }^{\circ} \mathrm{C}$ the austenite decomposes to different ferrite morphologies. The austenite to ferrite decomposition starts with the formation of allotriomorphic ferrite at the prior $\gamma-\gamma$ boundaries. With continued cooling, the Widmanstätten ferrite nuclease at ferrite/austenite boundaries and extends into the untransformed austenite-grain interiors. Further cooling to low temperatures, the acicular ferrite would nucleate on the inclusion. If there are no potent inclusions, bainitic ferrite might form instead of acicular ferrite, from the remaining austenite.

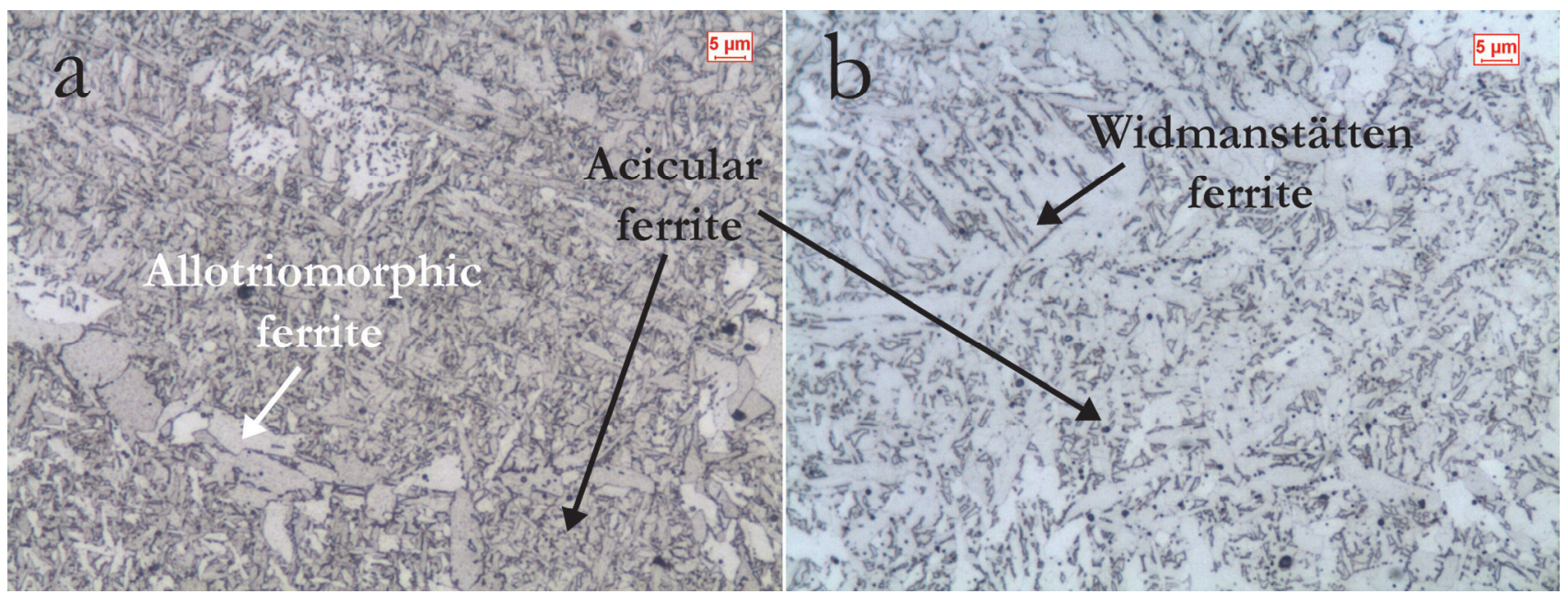

Figure 5: Micrograph of the fusion zone before (a) and after (b) TIG-dressing.

The heat affected zone (HAZ) of the as-welded joint was mainly composed of bainite while after TIG-dressing a mixture of bainite and tempered bainite was detected between the FZ and the parent metal (Fig. 6).

Fig. 7 shows the microhadness profile across the weld bead of the joint after TIG-dressing. It is noted that the different carbon amounts contained in the two plates result in a non-symmetric microhardness profile. The lower the carbon content, the lower the measured hardness values both in HAZ and parent metal. 


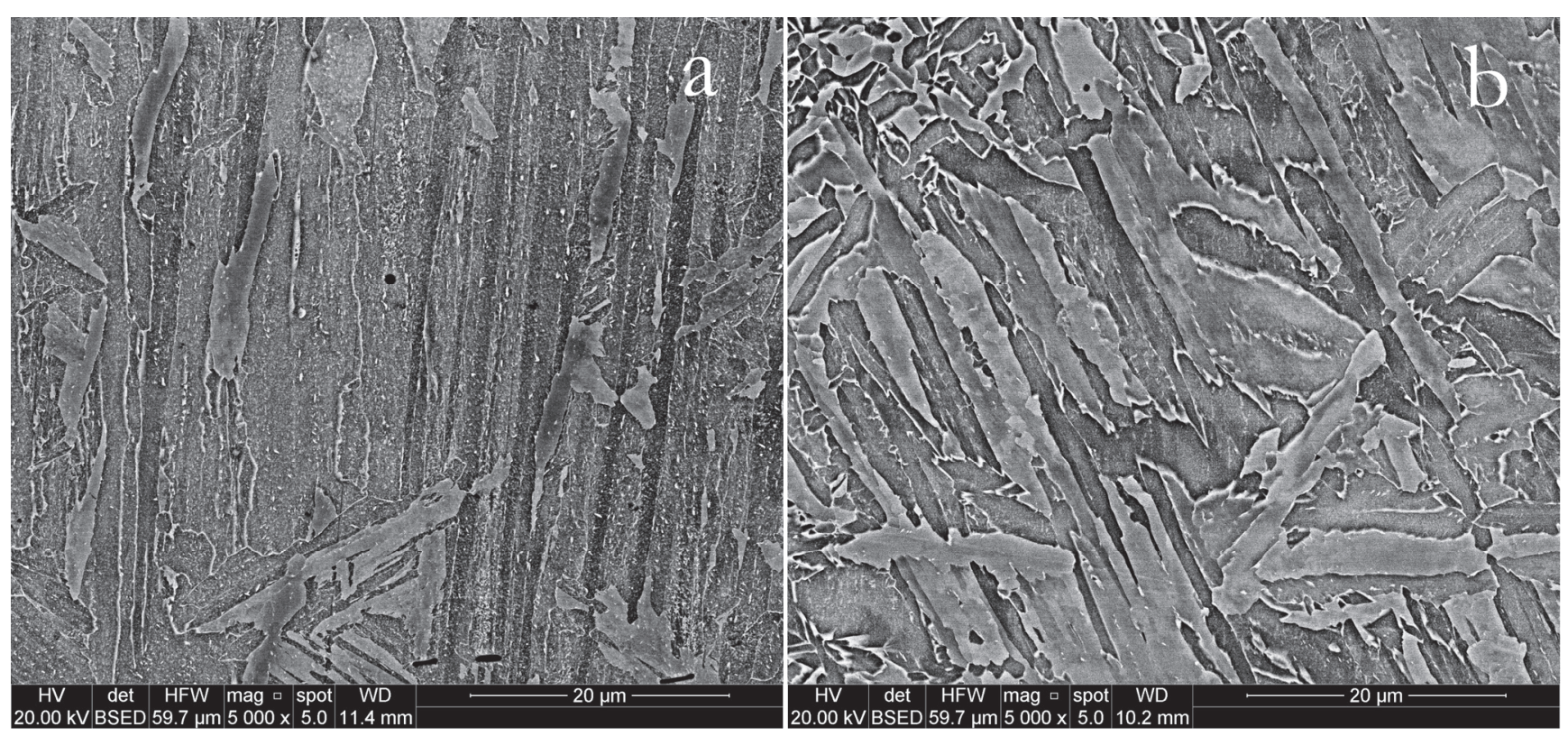

Figure 6: SEM micrograph of the HAZ before (a) and after (b) TIG-dressing.

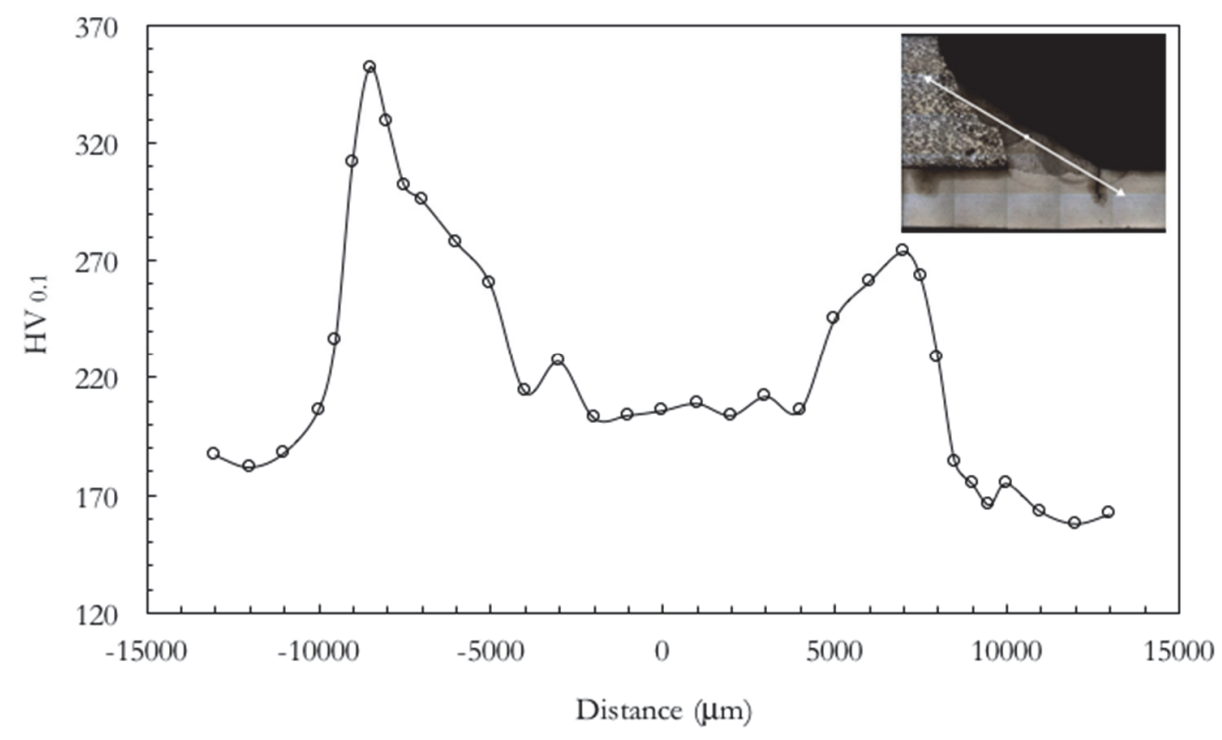

Figure 7: Microhardness profile across the weld bead.

Fig. 8 shows the temperature distribution at the point when the fusion zone has its maximum width (the fusion zone is shown in red). It also shows, as comparison, the macrograph of the joint cross section before and after TIG-dressing. It has to be underlined that the heat source and welding parameters are estimated by the comparison between the predicted and real fusion zone shape and dimensions and a sound agreement is obtained (Fig. 8).

The proportional distributions of phases after cooling with a comparison with experimental results are shown in Fig. 9. According to numerical simulation, each FZ is characterised by ferrite. However, it is worth noting that the model does not distinguish its different morphologies shown in metallurgical analysis (allotriomorphic, acicular and Widmanstatten ferrite). The heat-affected zone (HAZ) is instead characterized by a balanced amount of bainite and tempered bainite. SEM micrograph (Fig. 9) and micro-hardness measurements (Fig. 7) confirm the obtained numerical results. 

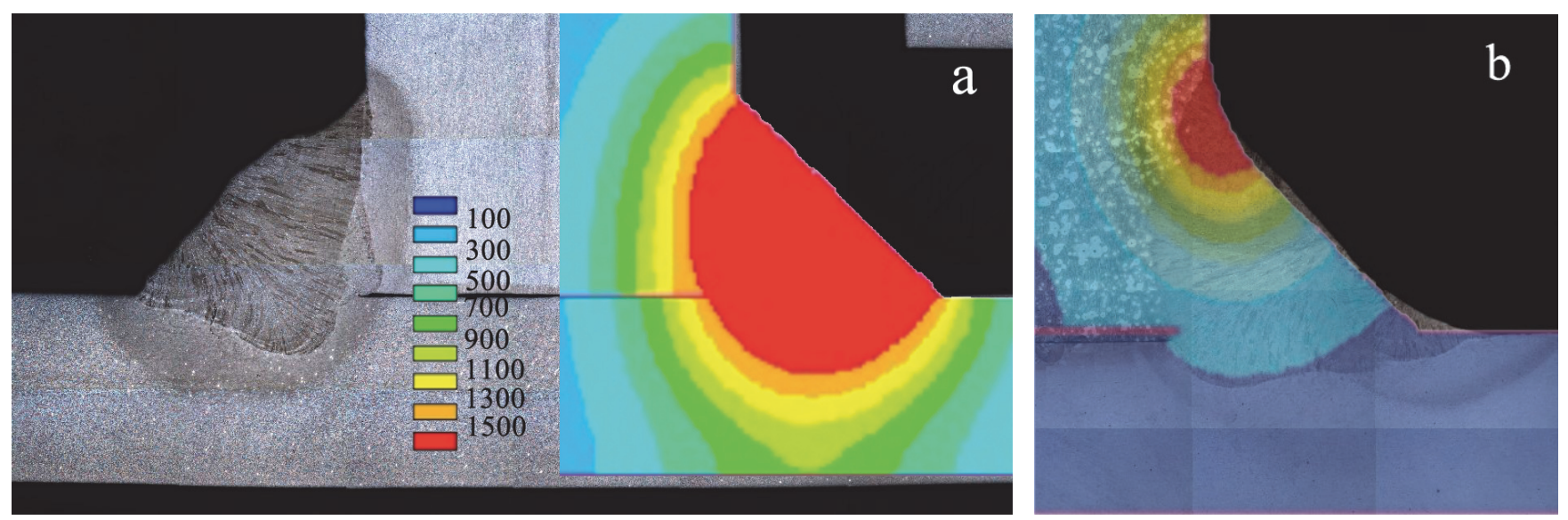

Figure 8: Temperature distribution ( $\mathrm{T}$ ) at the instant of maximum extension of the FZ induced by welding (a) and TIG-dressing (b).

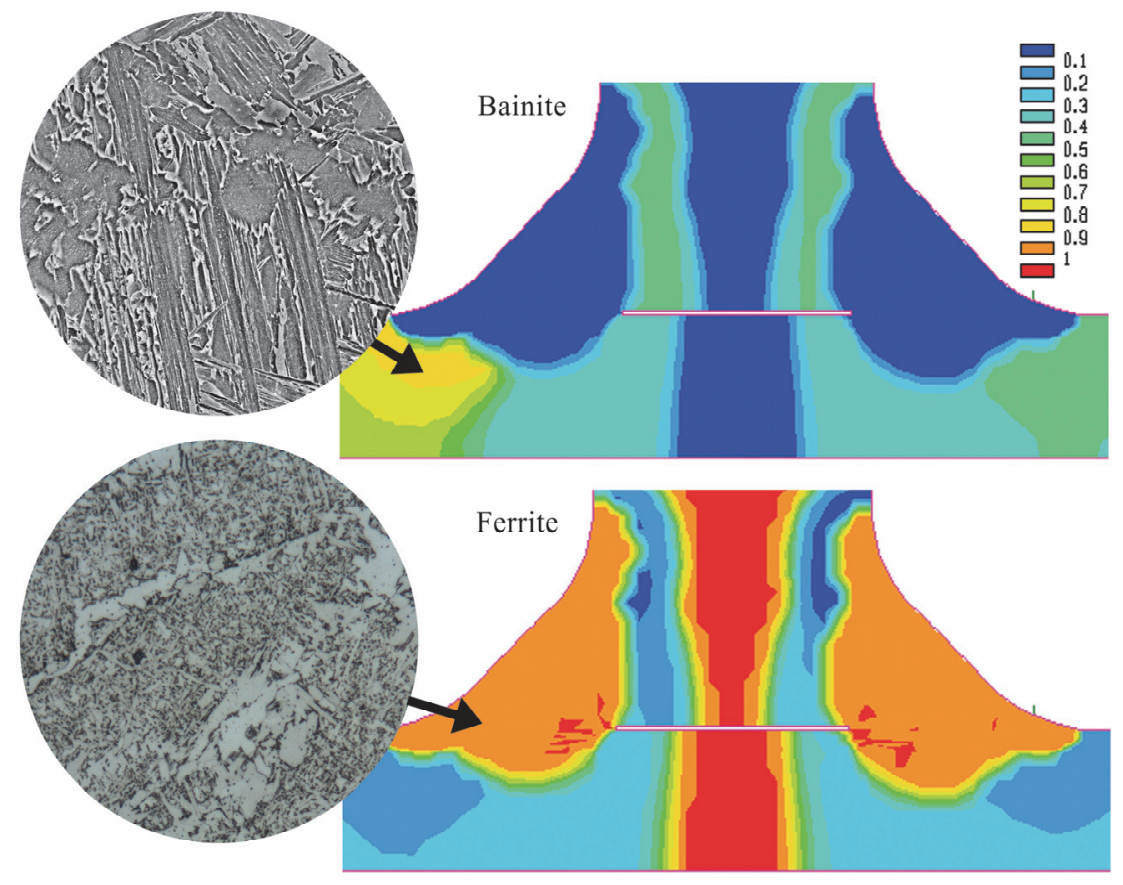

Figure 9: Bainite and Ferrite proportion after TIG-dressing.

In recent literature [21] it has been shown that if the weld is modeled as a sharp V-notch angle with a toe radius equal to zero, the residual stress distribution in that zone follows the William's solution [22]. In particular, that stress distribution has been found to be asymptotic with the singularity degree depending on the $\mathrm{V}$-notch angle. Boundaries conditions and phase transformations have a major influence on determining the sign of such asymptotic stress filed. Under isostatic boundaries conditions, like those used in this work, the residual stress field is positive due to phase transformations effects (volume change and transformation plasticity) during cooling (Fig. 10) [23]. The intensity of the asymptotic residual stress field is given by the so called Residual Notch Stress Intensity Factor (R-NSIF) that was used in recent literature to quantify the effect of residual stress on fatigue strength of welded joints [24-26] in the high-cycle fatigue regime.

Thanks to the remelting and the consequent reprofiling of the weld tip zone operated by the TIG-dressing process, the calculated residual stress distribution is no longer singular as it can be observed in Fig. 11. In particular, the residual stress becomes compressive with a huge reduction of its concentration. Such effects are in agreement with the improved fatigue strength observed in welded joints subjected to TIG-dressing. Finally, it is observed that even if a $2 \mathrm{D}$ model is not able to correctly capture the residual stress distribution in the welded joint, a qualitative estimation obtained in this work may be useful to understand the effect of TIG-dressing on the residual stress redistribution. In the next work the simulation will be improved by using a 3D model. 

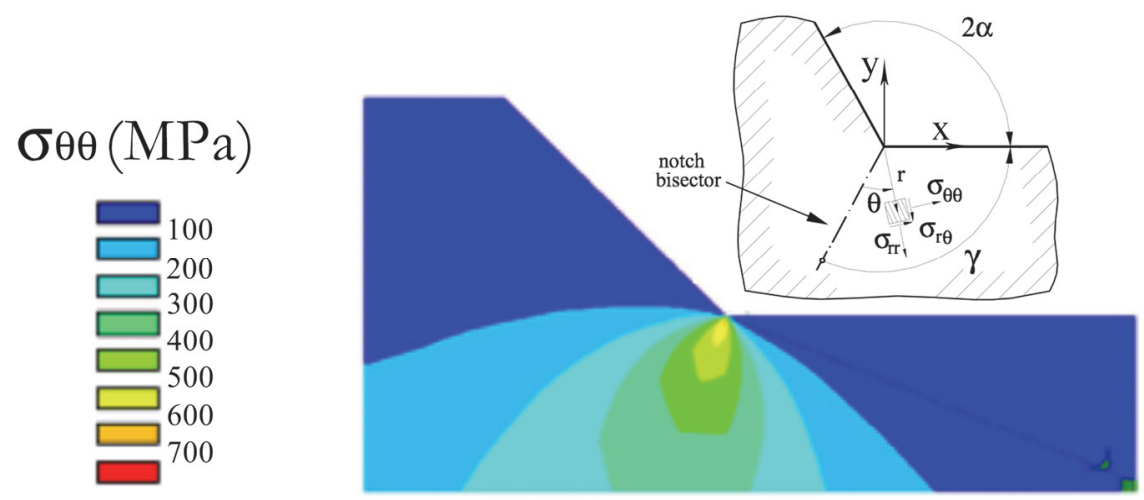

Figure 10: Stress distribution near the weld toe of the as-welded joint and the used reference system

(a)

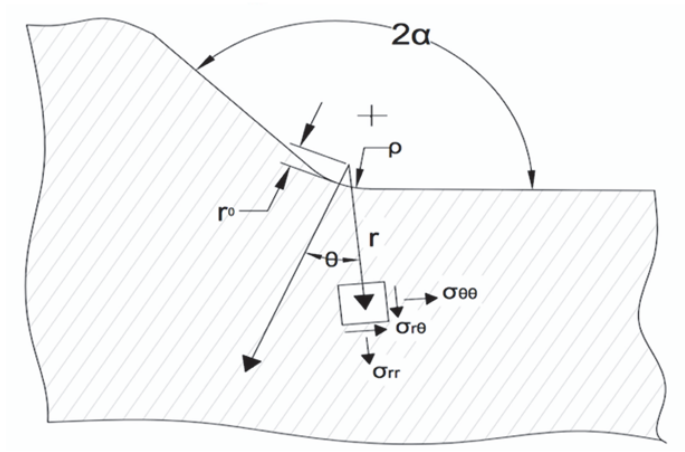

(b)

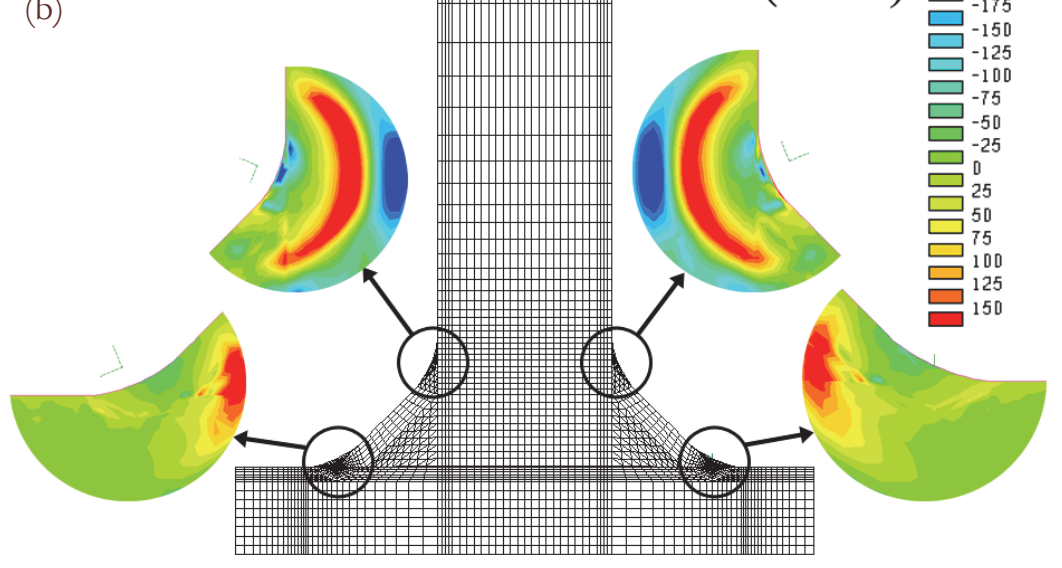

Figure 11: Local reference system (a), according to the blunt V-Notch theory, and residual stress distribution after TIG-dressing (b).

\section{CONCLUSIONS}

A simplified model was proposed to simulate the TIG-dressing process without using the fluid-mechanics coupled computation. The geometry variation of the weld tip zone induced by remitting was simulated by the use of the activation-deactivation function of elements. The welding and heat source parameters were calculated according to the metallurgical observation of fusion and heat affected zone with a good correspondence between experimental and numerical results. The drawback of the proposed model is the need to know 'a-priori' the weld tip radius obtained after welding. On the other hand, to the authors best knowledge, it is the first model present in literature, applied to a real joint, able to capture the residual stress redistribution promoted by TIG-dressing. Even if the residual stress redistribution agrees with the improved fatigue strength observed in welded joints subjected to TIG-dressing, authors are aware that a future improvement obtained by using a $3 \mathrm{~d}$ model will be necessary to capture the real redistribution of the residual stress.

\section{REFERENCES}

[1] Kirkhope, K.J., Bell, R., Caron, L., Basu, R.I. and Ma, K.-T. (1999). Weld detail fatigue life improvement techniques. Part 1: review. Marine Structures 12, pp. 447-474.

[2] Haagensen, P.J. and Maddox, S.J. (2001). IIW recommendations on post weld improvement of steel and aluminium structures. IIW Commission XIII.

[3] van Es, S.H.J, Kolostein, M.H., Pijpers, R.J.M. and Bijlaard, F.S.K. (2013). TIG-dressing of high strength steel butt welded connections - Part 1: weld toe geometry and local hardness. Procedia Engineering 66, pp. $216-225$.

[4] van Es, S.H.J, Kolostein, M.H., Pijpers, R.J.M. and Bijlaard, F.S.K. (2013). TIG-dressing of high strength steel butt welded connections - Part 2: physical modelling and testing. Procedia Engineering 66, pp. $126-137$. 
[5] Dahle, T. (1998). Design fatigue strength of TIG-dressed welded joints in high-strength steels subjected to spectrum loading. International Journal of Fatigue 20 (9), pp. 677-681.

[6] Pedersen, M. M., Mouritsen, O.Ø., Hansen, M.R., Andersen, J.G. and Wenderby, J. (2009). Comparison of Post Weld Treatment of High Strength Steel, Welded Joints in Medium Cycle Fatigue, IIW doc. XIII-2272-09

[7] Haagensen, P.J. Drågen, A. Slind, T. Ørjasæter, O. (1987). Prediction of the improvement in fatigue life of welded joints due to grinding, TIG dressing, weld shape control and shot peening, ECSC Offshore Conference on Steel in Marine Structures, Delft.

[8] Ferro, P., Bonollo, F. and Tiziani, A. (2005). Laser welding of copper-nickel alloys: a numerical and experimental analysis. Science and Technology of Welding and Joining, 5(3), pp. 299-310.

[9] Ferro P., Porzner, H., Tiziani, A. and Bonollo, F. (2006). The influence of phase transformations on residual stresses induced by the welding process - 3D and 2D numerical models. Modelling Simul. Mater. Sci. Eng. 14, pp. 117-136.

[10] Akbari, S.A.A. and Miresmaeili, R. (2008). Experimental and numerical analyses of residual stress distributions in TIG welding process for 304L stainless steel. Journal of Materials Processing Technology 208, pp. 383-394.

[11] Das R. and Cleary, P.W. (2016). Three-dimensional modelling of coupled flow dynamics, heat transfer and residual stress generation in arc welding processes using the mesh-free SPH method. Journal of Computational Science 16, pp. 200-216.

[12] Vemanaboina, H., Akella, S. and Buddu, R.K. (2014). Welding process simulation model for temperature and residual stress analysis. Procedia Materials Science 6, pp. 1539 - 1546.

[13] Hildebrand, J., Starcevic, I., Werner, F., Heinemann, H. and Köhler, G. (2006). Numerical simulation of TIG-dressing of welded joints. Joint International Conference on Computing and Decision Making in Civil and Building Engineering. June 14-16 - Montreal, Canada.

[14] Ferro, P., Bonollo, F. and Tiziani, A. (2010). Methodologies and experimental validations of welding process numerical simulation. Int J Computational Materials Science and Surface Engineering 3, pp. 114-32.

[15] Ferro, P., Berto, F. and James, M.N. (2017). A simplified model for TIG-dressing numerical simulation. Modelling Simul. Mater. Sci. Eng. 25, 035012

[16] Ferro, P., Berto, F. and Lazzarin, P. (2006). Generalized stress intensity factors due to steady and transient thermal loads with applications to welded joints. Fatigue and Fracture of Engineering Materials and Structures 29(6), pp. 440453

[17] Leblond, J.B. and Devaux, J. (1984). A new kinetic model for anisothermal metallurgical transformations in steels including the effect of austenite grain size. Acta Metall 32, pp. 137-46.

[18] Koistinen, D.P. and Marburger, R.E. (1959). A general equation prescribing extent of austenite-martensite transformation in pure iron-carbon alloys and carbon steels. Acta Metall 7, pp. 59-68.

[19] Goldak, J., Chakravarti, A. and Birbby, M. (1984). A new finite element model for welding heat sources. Metallur Trans B 15b, pp. 299-305.

[20] Babu, S.S. (2004). The mechanism of acicular ferrite in weld deposits. Current Opinion in Solid State and Materials Science 8, pp. 267-278.

[21] Ferro, P., Petrone, N. (2009). Asymptotic thermal and residual stress distributions due to transient thermal loads. Fatigue Fract Eng Mater Struct 32, pp. 936-948.

[22] Williams, M.L. (1952). Stress singularities resulting from various boundary conditions in angular corners of plates in tension. J Appl Mech 19, pp. 526-528.

[23] Ferro, P. (2012). The influence of phase transformations on the asymptotic residual stress distribution arising near a sharp V-notch tip. Modelling Simul. Mater. Sci. Eng. 20(8) 085003, DOI:10.1088/0965-0393/20/8/085003.

[24] Ferro, P. (2014). The local strain energy density approach applied to pre-stressed components subjected to cyclic load. Fatigue Fract Eng Mater Struct 37, pp. 1268-1280.

[25] Ferro P. and Berto F. (2016). Quantification of the influence of residual stresses on fatigue strength of Al-alloy welded joints by means of the local strain density approach. Strength of Materials, 48(3), pp. 426-436, DOI:10.1007/s11223-016-9781-0

[26] Ferro P., Berto F. and James N.M. (2016). Asymptotic residual stresses in butt-welded joints under fatigue loading. Theoretical and Applied Fracture Mechanics 83, pp. 114-124, DOI:10.1016/j.tafmec.2016.02.002

\section{NOMENCLATURE}

a Molten pool geometrical parameter [mm]

b Molten pool geometrical parameter [mm] 
$\mathrm{c}_{1} \quad$ Molten pool geometrical parameter $[\mathrm{mm}]$

$\mathrm{c}_{2} \quad$ Molten pool geometrical parameter $[\mathrm{mm}]$

$\mathrm{f}_{1} \quad$ Constants for the energy distribution of the heat flux

$\mathrm{f}_{2} \quad$ Constants for the energy distribution of the heat flux

$\mathrm{Q} \quad$ Absorbed power $[\mathrm{W}]$, with $\mathrm{Q}=\eta \mathrm{Q}^{*}$

Q* Power Input [W]

$\mathrm{v} \quad$ Welding or TIG-dressing speed $\left[\mathrm{mms}^{-1}\right]$

$\eta \quad$ Efficiency

$\tau \quad$ Total duration of time before the welding source has traversed the transverse cross section of the plate [s]

$2 \alpha \quad$ V-notch opening angle

$\sigma_{\theta \theta}$ Residual stress, $\theta \theta$ component [MPa]

$\rho$ toe-radius $[\mathrm{mm}]$

$\tau$ Time $[\mathrm{s}]$

$\mathrm{T} \quad$ Temperature $\left[{ }^{\circ} \mathrm{C}\right]$ 